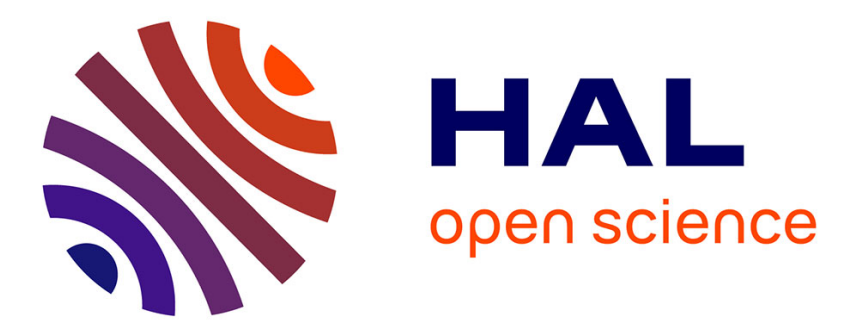

\title{
In situ insight into the unconventional ruthenium catalyzed growth of carbon nanostructures
}

\author{
M. Bahri, K. Dembélé, C. Sassoye, D. P Debecker, S. Moldovan, A. Gay, Ch \\ Hirlimann, C. Sanchez, O. Ersen
}

\section{- To cite this version:}

M. Bahri, K. Dembélé, C. Sassoye, D. P Debecker, S. Moldovan, et al.. In situ insight into the unconventional ruthenium catalyzed growth of carbon nanostructures. Nanoscale, 2018, 10 (31), pp.14957 - 14965. 10.1039/C8NR01227J . hal-01912233

\section{HAL Id: hal-01912233 \\ https: / hal-ifp.archives-ouvertes.fr/hal-01912233}

Submitted on 5 Nov 2018

HAL is a multi-disciplinary open access archive for the deposit and dissemination of scientific research documents, whether they are published or not. The documents may come from teaching and research institutions in France or abroad, or from public or private research centers.
L'archive ouverte pluridisciplinaire HAL, est destinée au dépôt et à la diffusion de documents scientifiques de niveau recherche, publiés ou non, émanant des établissements d'enseignement et de recherche français ou étrangers, des laboratoires publics ou privés. 


\title{
In situ insight into the unconventional ruthenium catalyzed growth of carbon nanostructures $\dagger$
}

\author{
M. Bahri, ${ }^{a, b}$ K. Dembélé, a C. Sassoye, ${ }^{c}$ D. P. Debecker, (iD d S. Moldovan, ${ }^{a, e}$ \\ A. S. Gay, (D ${ }^{\text {b }}$ Ch. Hirlimann, ${ }^{a}$ C. Sanchez ${ }^{\text {,f }}$ and O. Ersen (D *a,g,h
}

\begin{abstract}
We report on the in situ analysis of the growth process of carbon nanostructures catalyzed by Ru nanoparticles using syngas, a mixture of hydrogen and $\mathrm{CO}$, as the carbon source at a medium temperature $\left(500{ }^{\circ} \mathrm{C}\right)$. The structural modifications of the dual nanotube/nanoparticle system and the general dynamics of the involved processes have been directly followed during the growth, in real time and at the atomic scale, by transmission electron microscopy in an environmental gas cell at atmospheric pressure. After a reduction step under hydrogen and syngas, the particles became very active for the carbon growth. The growth rate is independent of the particle size which mainly influences the nanotube wall thickness. Other subtle information on the general behavior of the system has been obtained, as for instance the fact that the regular changes in the direction of the particle originate generally from the particle shape fluctuation. The main result is the evidence of a new growth mode in relation to the presence and the high instability of the ruthenium carbide phase which acts as a carbon reservoir. For the first time, a relaxation oscillation of the growth rate has been observed and correlated with the metal-carbide structural transition at the particle sub-surface.
\end{abstract}

Received 9th February 2018

Accepted 5th July 2018

DOI: 10.1039/c8nr01227j

rsc.li/nanoscale stand the carbon-metal interaction during the growth process. A wide variety of active nanocatalysts were used for growing carbon nanotubes or nanofibers through a catalytically assisted chemical vapor deposition process. Among them, the most active and least expensive catalysts are found in the Fefamily $(\mathrm{Fe}, \mathrm{Ni}, \mathrm{Co})^{7}$

To control and to optimize the growth and the subsequent properties of carbon nanostructures, crucial questions should be answered for which several in situ experiments and theoretical studies have been performed dealing with various nanoparticle catalysts ( $\mathrm{Ni}, \mathrm{Fe}, \mathrm{Au}, \mathrm{Co}, \mathrm{Pd}, \mathrm{Ru}$, etc.). ${ }^{8-15}$ What is the state (crystalline, liquid, fluctuating crystalline) and the nature of the active phase (carbide or metallic) of these nanoparticles? Do carbon atoms migrate on the surface and/or through the bulk of the nanoparticles? Is there a universal growth mechanism for all the metal catalysts and carbon sources?

Before discussing our own results, we present a short stateof-the-art on the subject that provides a direct insight, in real time, into the growth process at the nanometer scale. Various results were obtained in this respect by using in situ TEM based techniques, more particularly by using environmental TEM (ETEM) approaches. Hofmann et al. ${ }^{16}$ reported that $\mathrm{Ni}$ catalyst particles do exhibit a fast self-diffusivity while showing a long range crystalline order which can be assigned to a liquid-like behavior. Different physical states of the particles (solid, liquid, liquid-like) were mentioned as being involved in
Institut de Physique et Chimie des Materiaux de Strasbourg (IPCMS), UMR 7504 France

IFP Energies Nouvelles, Rond-Point de l'Échangeur de Solaize, BP 3, 69360 Solaize,

${ }^{c}$ Sorbonne Universités, UPMC Univ Paris06, Collège de France, Laboratoire de of Condensed Matter and Nanosciences - Molecules, Solids and Reacti (IMCN/MOST), Université Catholique de Louvain, Place Louis Pasteur, 1, Box Rouen, Avenue de l'Université, Saint Etienne du Rouvray, France

${ }^{f}$ Chaire de Chimie des Matériaux Hybrides, Collège de France, 11 Place Marcelin Berthelot, 75231 Paris, France

${ }^{g}$ University of Strasbourg Institute for Advanced Studies (USIAS), Strasbourg, France

${ }^{h}$ Institut Universitaire de France (IUF), Paris, France

$\dagger$ Electronic supplementary information (ESI) available. See DOI: 10.1039/ c8nr01227j 
the growth process. For instance, Tang et al. ${ }^{17}$ demonstrated that the physical state of the catalyst depends on the local kinetic conditions.

Another fundamental question in this field relates to the type of active phase involved in the growth process. For Fe and Ni catalysts, Hofmann et al. ${ }^{18}$ observed that the active phase of $\mathrm{Ni}$ and $\mathrm{Fe}$ is probably the crystalline metallic phase and not the oxide one. The carbide formation only happens in the case when Fe is present in very little amounts. They suggest that the carbide phase is not a necessity for the formation of CNTs. Note that, in the case of Ni-based catalysts, most of the studies show the active phase to be the metallic one. ${ }^{16,18,19}$

Yoshida et $a .^{20}$ showed a change in the crystal orientation of a Fe catalyst without any physical rotation of the whole nanoparticle in a mixture of $\left(\mathrm{C}_{2} \mathrm{H}_{2}: \mathrm{H}_{2}\right)$ at $P=10 \mathrm{~Pa}$ and $T=$ $600{ }^{\circ} \mathrm{C}$. They concluded that the particles have fluctuating crystalline morphologies and that the active phase is cementite, $\mathrm{Fe}_{3} \mathrm{C}$. For Fe-Mo-C catalysts, the same authors also showed a fluctuating crystalline morphology. ${ }^{21}$ By using image simulation, the structure of these fluctuating particles was demonstrated to be $(\mathrm{FeMo})_{23} \mathrm{C}_{6}$. Tang et al. ${ }^{17}$ concluded that during the nucleation and growth of CNTs, the iron catalyst is mainly in the carbide phase but the NP can also transform into metallic Fe at different growth stages. However, it is worth noting that the phase evolution of the catalyst during the growth process also depends on the carbon source; for instance, using Fe catalysts and CO carbon sources, the particles always remain in the carbide phase.

Kohigashi et $a .^{22}$ showed that Co nanoparticles have a quite inhomogeneous structure during CNT growth. In particular, the nanoparticles are made of a mixture of $\mathrm{Co}_{3} \mathrm{C}$ and hcp Co and other unidentified structures. The active phase seems to be $\mathrm{Co}_{3} \mathrm{C}$. These observations were confirmed by Lin et $a .^{23}$ They demonstrated the co-existence of Co and Cocarbide inside a single catalyst particle during the SWCNT (single wall carbon nanotube) growth.

CNT growth was also studied by using in situ TEM and Au nanoparticles as a catalyst. Tang et al. ${ }^{17}$ showed that no chemical reaction or phase transition occurred during the growth. The particle was in a quasi-liquid state or in a quasi-melting state. A graphitic shell is formed and partially detached to form a carbon cap. This cap grows into a CNT under suitable conditions. The same observation was confirmed by Hofmann et $a l .{ }^{18}$ They showed that a SWCNT nucleates through a lift-off process of the carbon cap. The carbon cap stabilization is guided by dynamical shape changes of the Au catalyst particle.

The growing mode of carbon nanostructures has been widely discussed in order to answer the second question: does carbon diffuse on the surface of the active phase particle or via the bulk? Various studies showed that there is no general behavior as the diffusion of the atoms depends on several parameters, among which the physical state of the particle solid, liquid or liquid-like can be of huge importance, as mentioned before. Following the classical Gibbs-Thomson equation, the melting points of metallic nanoparticles are decreased by about $2 / 3$ when their sizes reach $5 \mathrm{~nm} \cdot{ }^{24-26}$ Given the melting point of bulk ruthenium $(\mathrm{Ru})$ which is about $2250{ }^{\circ} \mathrm{C}$, the corresponding point for nanoparticles with $8 \mathrm{~nm}$ mean size can be estimated using a scaling law ${ }^{27}$ at about $1900{ }^{\circ} \mathrm{C}$. In addition, to estimate the physical state of nanoparticles, one can use the Tamman temperature at which the atoms or molecules of the solid acquire a sufficient energy for having appreciable mobility and reactivity and which can be approximated as one-half of the melting temperature of the chosen system, in our case about $800{ }^{\circ} \mathrm{C}$ for $8 \mathrm{~nm}$ sized particles. ${ }^{28}$ This temperature depends strongly not only on the size but also on the chemical composition of the particles. Therefore, at a temperature not very far from the Tamman one, the NPs might be in an intermediate physical state, between solid and liquid like phases.

Baker et $a l .{ }^{29}$ suggested that the catalyst (in the liquid state) cracks the carbon source molecules and dissolves the carbon atoms (from the gas phase) that do precipitate into solid state carbon fibers after reaching a supersaturated concentration. This growth model is called the vapor-liquid-solid (VLS) model and was used for studying the growth of silicon whiskers, ${ }^{30}$ nanorods and nanowires. ${ }^{31}$ Feng et al. ${ }^{32}$ showed that in both processes, the growth and gasification, the iron catalyst is in a liquid-like state and continuously changes shape, showing sometimes a lattice structure. Thus, they proposed to slightly modify the VLS model into a VLLS one (vapor-liquid likesolid). However, various studies contradicted the liquid or liquid-like particle state. ${ }^{33}$ They have shown that the catalyst particles are crystalline, during CNT growth which suggests a vapor solid-solid model, VSS. ${ }^{19}$ This growth model explains the formation of carbon nanotubes without the carbon dissolving inside the particle. Dai ${ }^{34}$ and others supported a similar nucleation mechanism of CNTs in catalyst CVD which they named the "yarmulke" mechanism. Carbon atoms adsorbed on the surface of a nanoparticle form a carbon cap after agglomeration that reduces the surface energy of the nanoparticle. Then, this cap is lifted from the nanoparticle leading to the initiation of the CNT growth process.

Recently, Lin et al. ${ }^{23}$ identified two sources of carbon supporting the SWCNT growth; the surface diffusing $\mathrm{C}$ atoms that are incorporated at a constant rate and carbon atoms diffusing out of metastable carbides inside the particle bulk, incorporated at fluctuating time intervals.

In this general context, $\mathrm{Ru}$ was also used as a catalyst for growing carbon nanostructures. ${ }^{35-38}$ Various studies pointed out that carbon solubility in $\mathrm{Ru}$ is lower than that in the Fefamily and that the $\mathrm{Ru}$ carbide phase is known to be very unstable. ${ }^{37,38}$ The mechanism based on the solubility of carbon in a metallic catalyst cannot be valid which implies that another approach has to be considered for the growth process on Ru-catalysts, compared to the Fe-family.

In this article, we show for the first time the in situ growth of carbon nanostructures with a fishbone morphology catalyzed by $\mathrm{Ru}$ nanoparticles. To achieve this, we exploit the fundamental advantage of an environmental cell which allows TEM imaging in real time of the CNT growth process and the dynamical changes of the catalyst. The growth of carbon nano- 
structures was performed at atmospheric pressure which reproduces the realistic conditions of the chemical vapor deposition technique (CVD).

\section{Experimental details}

\subsection{Catalyst preparation}

A highly stable colloidal suspension of monodispersed $\mathrm{RuO}_{2}$ nanoparticles was obtained by the dropwise addition of $15 \%$ $\mathrm{v} / \mathrm{v} \mathrm{H}_{2} \mathrm{O}_{2}$ aqueous solution into $0.011 \mathrm{M} \mathrm{RuCl}_{3} \cdot x \mathrm{H}_{2} \mathrm{O}(x=3-5)$ aqueous solution for a final concentration of $\mathrm{Ru} \approx 0.007$ M. The solution was heated at $95{ }^{\circ} \mathrm{C}$ for $2 \mathrm{~h}^{39}$ Once cooled to room temperature, an appropriate amount of $\mathrm{TiO}_{2}$ powder (P25, Sigma Aldrich) was added to the colloidal suspension of $\mathrm{RuO}_{2}$ nanoparticles to yield $7 \mathrm{wt} \%$ of $\mathrm{Ru}$ in the final catalyst. Water from the mixture was then removed by rotary evaporation. The resulting powder, $2 \mathrm{~nm} \mathrm{RuO}_{2}$ nanoparticles homogenously dispersed onto $\mathrm{TiO}_{2}$ particles, ${ }^{40}$ was then calcined at $150^{\circ} \mathrm{C}$ for $16 \mathrm{~h}$ in static air. ${ }^{41}$

\subsection{In situ TEM experiments}

TEM/STEM experiments were performed using a $\mathrm{C}_{\mathrm{s}}$-corrected JEOL JEM-2100F microscope operated at $200 \mathrm{keV}$, equipped with an UltraScan 1000 CCD array detector. In situ observations were carried out using a Protochips Atmosphere device. $^{42}$ The sample was placed between two micro-electricalmechanical systems (MEMS)-based closed cell (SiN windows with a chemical formula close to $\mathrm{Si}_{3} \mathrm{~N}_{4}$ but slightly silicon rich). The temperature and the gas flow in the cell are controlled by the heating holder and a gas delivery manifold, respectively. All the indicated temperatures are based on the company provided calibration. A schematic representation of the in situ system is shown in the ESI. $\dagger$

The catalyst powder was ground, dispersed in ethanol and dropcast on the SiN membrane acting as a heater element. The catalyst was first thermally treated under $\mathrm{Ar}$ gas at $600{ }^{\circ} \mathrm{C}$ for 80 minutes. Then a reduction step was performed under a $\mathrm{H}_{2}$ atmosphere at $800{ }^{\circ} \mathrm{C}$ for $1 \mathrm{~h}$. The growth of carbon nanostructures has been carried out using a mixture of $\mathrm{H}_{2} / \mathrm{CO}(2: 1)$ at $500{ }^{\circ} \mathrm{C}$. The medium temperature is one of the lowest reaction temperatures reported until now and may be of great interest for the scale up process of the carbon nanotube growth. All observations were performed at atmospheric pressure.

The high energy irradiation from the electron beam of the microscope may have a considerable effect on the decomposition process of the initial gases. ${ }^{43}$ Several non-irradiated regions were checked only at the end of the in situ growth experiment, after the evacuation of the gas carbon source, and show the presence of similar carbon structures evidencing thus a negligible effect of the electron beam irradiation on the growth process.

\section{Results and discussion}

Before the growth of carbon nanostructures, the catalyst was activated by using a two-step treatment consisting of: (i) annealing under $\mathrm{Ar}$ at atmospheric pressure at $600{ }^{\circ} \mathrm{C}$ for $1 \mathrm{~h}$ and (ii) a reduction process under hydrogen at $800{ }^{\circ} \mathrm{C}$ for $1 \mathrm{~h}$ for reducing the oxidized catalyst particles. Such a high temperature for the reduction step was imposed by association with a real CVD process. ${ }^{35,36}$ Fig. 1 illustrates the evolution of the $\mathrm{Ru}$ catalyst during the activation process. Note that the $\mathrm{RuO}_{2}$ nanoparticles can be found in two different morphologies: epitaxial layers generally on rutile $\mathrm{TiO}_{2}$ and nanoparticles on anatase $\mathrm{TiO}_{2} \cdot{ }^{40,41}$ The epitaxial layer of $\mathrm{RuO}_{2}$ is visible on the rutile particle when the catalyst is brought up to $200^{\circ} \mathrm{C}$ under $\mathrm{Ar}$, but this interaction is visibly fragmented at higher temperature (white arrows in Fig. 1(a) and (b)), probably because a partial reduction already occurs at this stage. However, no visible sintering effect can be observed after this annealing step, except for only a few particles localized on anatase. The reductive treatment with $\mathrm{H}_{2}$ at atmospheric pressure and high temperature $\left(800{ }^{\circ} \mathrm{C}\right)$ results in a more pronounced sintering effect leading to a small number of large (about $10 \mathrm{~nm}$ ) Ru particles (yellow arrow in Fig. 1(c)).

After the activation of the particles, different temperatures and $\mathrm{CO} / \mathrm{H}_{2}$ ratios in the gas precursor have been explored using the E-cell set-up experiment. The best parameters which provided a dynamical equilibrium in the growth process and the highest growth rate were found to be $1 / 2$ for the $\mathrm{CO} / \mathrm{H}_{2}$ ratio and $500{ }^{\circ} \mathrm{C}$ for the temperature. It is important to keep in
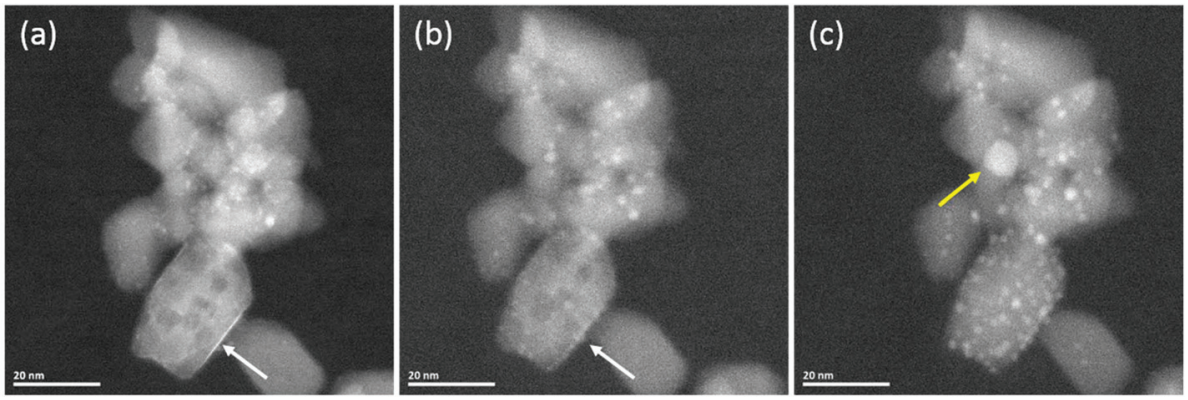

Fig. 1 STEM images of the $\mathrm{RuO}_{2} / \mathrm{TiO}_{2}$ catalyst. Images acquired under Ar at $200{ }^{\circ} \mathrm{C}$ (a), after the annealing step under Ar at $600{ }^{\circ} \mathrm{C}$ (b), and after reduction under $\mathrm{H}_{2}$ at $800^{\circ} \mathrm{C}$ (c). 
mind that the fundamental role of hydrogen in the process is to avoid the deactivation of the catalyst and to enhance the growth reaction mechanism, as suggested by several studies from the literature. ${ }^{4,45}$

A real time sequence for the growth of the carbon nanostructure nanofibers is depicted in Fig. 2 (Video S1 in the ESI $\dagger$ ). The three carbon nanostructures pointed at by arrows (Fig. 2(a-c)) are grown on three spatially close Ru nanoparticles with sizes between 7 and $10 \mathrm{~nm}$. Fig. 2(d) shows the mean growth rate as a function of the particle size deduced by dividing the total length of the grown carbon nanostructure by the time during which the particle is catalytically active. By analyzing 10 individual situations with particles sizes ranging from 1 to $10 \mathrm{~nm}$, the growth rates have been measured and range between 1 and $4 \mathrm{~nm} \mathrm{~s}^{-1}$. The size of the Ru nanoparticle does not seem to have a direct influence on the nanotube growth rate, since no correlation can be established. However, regarding the influence of the particle size on the growth process, it can be clearly observed that this parameter is directly correlated with the thickness of the grown carbon wall (Fig. 2(e)). This behavior is generally accepted in the field of carbon nanotube growth by CVD: the larger the particle size, the higher its catalytically active surface and consequently the number of dissociated molecules.

In order to better understand the growth mechanism related to the dynamical evolution of the catalyst particles, in situ analyses with a higher resolution were performed. This allowed following the microstructural changes of both the carbon structures and the Ru catalyst. Fig. 3 shows the shape fluctuation of a $\mathrm{Ru}$ nanoparticle with a mean size of about
$10 \mathrm{~nm}$ during the growth of carbon nanostructures (Video S2 in the ESI $\dagger$ ). After about $28 \mathrm{~s}$ in the $\mathrm{CO} / \mathrm{H}_{2}$ atmosphere, the particle shape fluctuates from a cubic morphology (Fig. 3a) to a truncated octahedral one (Fig. 3b). Then, 9 seconds later, the particle took quite a spherical shape (Fig. 3c) and the apparent size of the particle decreased to a minimum one suggesting that it globally contains fewer atoms. In addition, as suggested by the Fast Fourier Transform (FFT) analysis of the images (insets in Fig. 3a where the various visible planes are pointed at with different colors of arrows), no visible diffraction spot can be observed at the last position. This suggests the possible structural or chemical modifications with respect to the initial state. Intuitively, these changes can be explained by the dissolution of carbon atoms in the particle bulk, leading to carbide, and by the fluctuation of their total concentration with time: this dissolution reaches a saturation threshold during a period in which the growth rate of the carbon nanostructure is slow and after which a high carbon amount is rejected from the particle and forms the graphitic layer of the carbon nanostructures. Note that these layers do appear at the lateral facets of the particle suggesting a very low wetting of the particle surface by carbon, in agreement with the carbide phase in the sub-surface area. However, from this preliminary analysis, we can conclude that the observed shape fluctuation can be directly related to the change in the growth direction (which is observed for the particles highlighted by yellow arrows in Fig. 2a and b) and thus as one of the parameters responsible for the non-linear growth of the carbon structure. A second example of the particle shape fluctuations is added in the ESI (Fig. S2†).

1

(d)

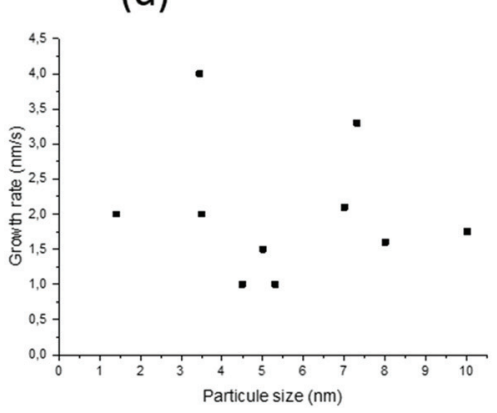

(e)

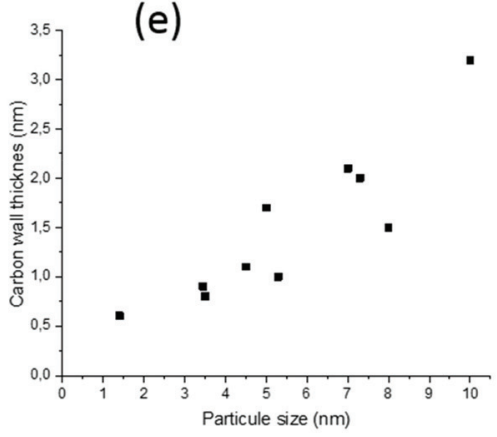

Fig. 2 Image sequence of the carbon nanostructures (Fishbone type) growth from three Ru nanoparticles with different sizes (arrows) at $t_{0}$ (a), $t=$ $10 \mathrm{~s}(\mathrm{~b})$, and $t=20 \mathrm{~s}$ (c). The growth rate and the thickness of the carbon wall versus the Ru particle sizes (d) and (e). 

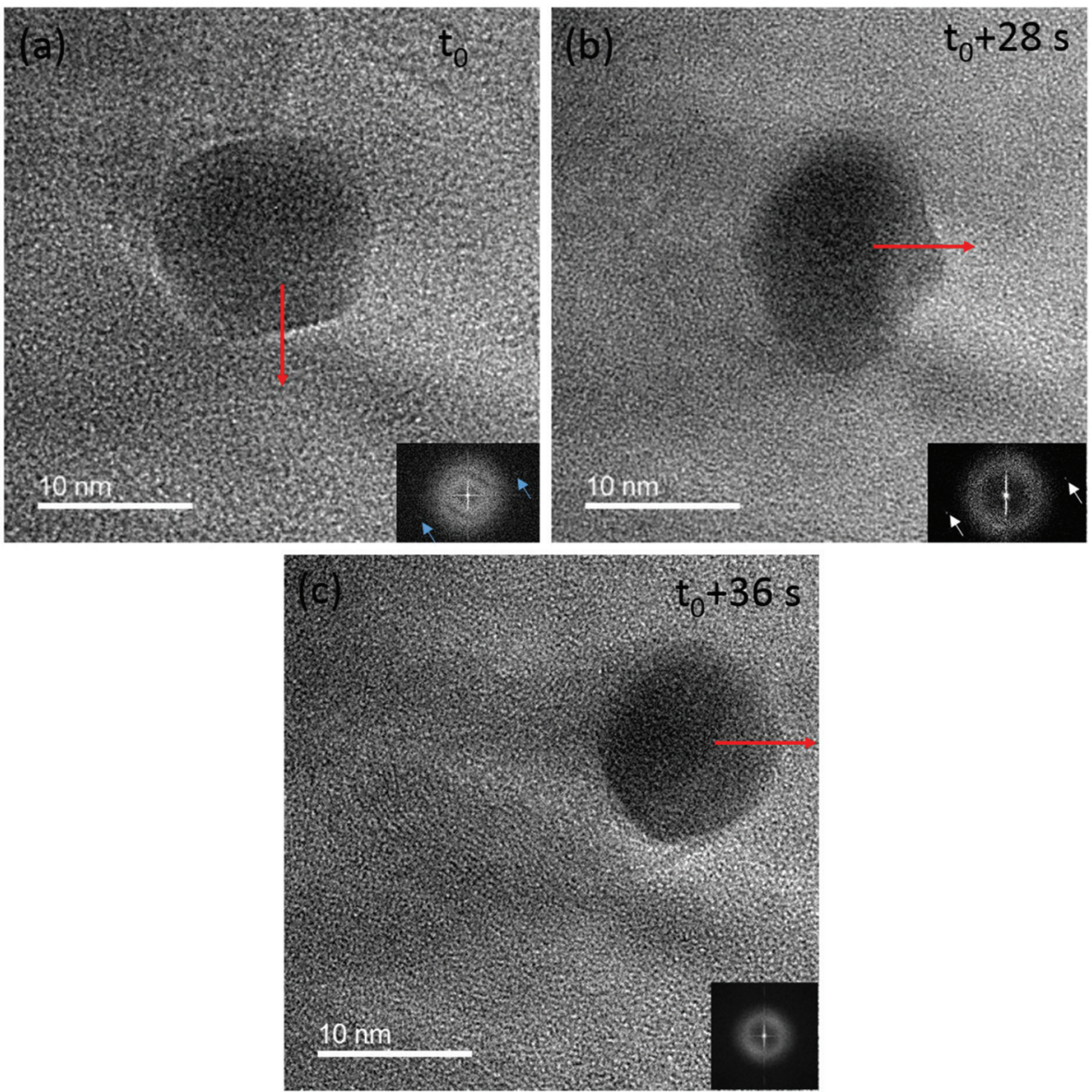

Fig. 3 TEM images showing the particle morphology fluctuation from cubic (a), then octahedral (b-d), and $t_{0}$ spherical (e-f). Red arrows highlight the growth direction and green arrows indicate the step edge events. Inset images: fast Fourier transforms on which the different planes are pointed at by two colors of arrows (blue $d=0.187 \mathrm{~nm}$, white $d=0.201 \mathrm{~nm}$ ).

From the kinetics point of view, a deeper analysis of the growth process is obtained by tracking the trajectory of the particle during the in situ process. Fig. 4 shows the time dependence of the traveled distance of one of the typical particles having a size of about $7 \mathrm{~nm}$. The main result is that the growth rate varies with time looking like a non-linear relaxation oscillation with a typical time variation of about $11 \mathrm{~s}$ and the growth rate between 0.5 and $1.5 \mathrm{~nm} \mathrm{~s}^{-1}$. We may compare this process with the one that takes place in a capacitive relaxation oscillator with a neon lamp threshold device. Following the discussion above (Fig. 3), we consider an interplay between a metallic and a carbide-like phase. As time passes, the metal nanoparticle fills up with carbon. As a consequence, the mean binding energy between the $\mathrm{C}$ and the $\mathrm{Ru}$ atoms in the particle drops down to a value that, at some point, is small enough for the interatomic bonds to be simply thermally broken.

Carbon atoms are then rapidly released contributing to the building-up of the nanotube. It then takes some time for the particles to be filled again with carbon atoms as the mean binding energy recovered its original higher value during the draining process. As the observation was performed at a temp-

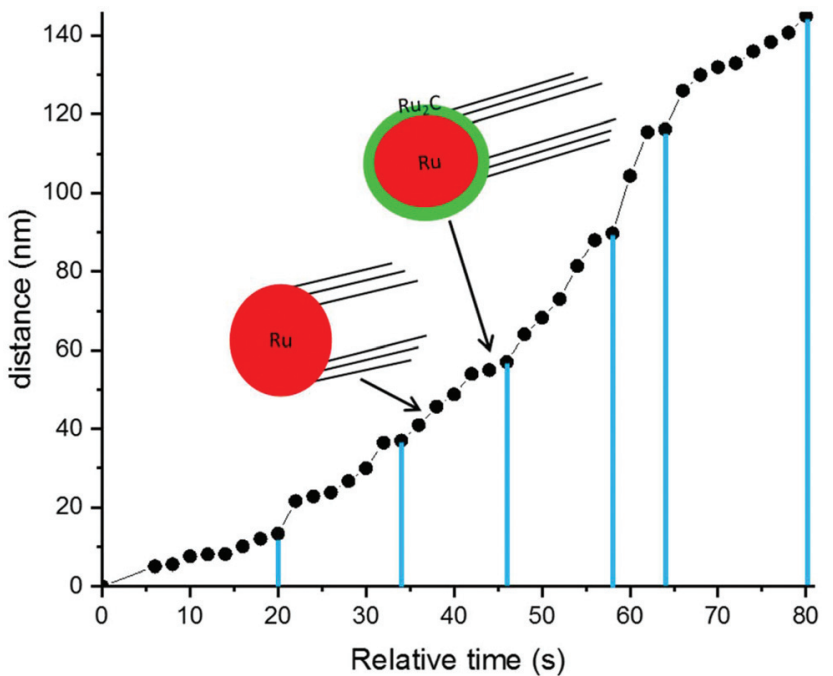

Fig. 4 Traveled distance of the Ru nanoparticle as a function of time. The two configurations of the structures of Ru-based particles corresponding to the low and high growth rates (associated with the low and high slopes of the experimental curve) are also indicated. 
erature of $500{ }^{\circ} \mathrm{C}$, we evaluate the threshold binding energy that controls the relaxation oscillation to be of the order of $41 \mathrm{meV}$. It seems clear that both phases, the metallic one and the carbide-like, are involved in the growth process. From our results one can predict that the relaxation oscillation should be sensitive to the applied temperature that controls the threshold of the draining process and it should also depend on the cube of the particle size that controls the filling time of the particle.

To confirm the assumption, a deeper analysis of the highresolution data recorded during the in situ study was performed. To determine the most active phase (carbide or metallic) for the growth of carbon nanostructures, the crystalline structure of the Ru NPs was investigated as a function of time. Fig. 5 shows a Ru wave plane reconstruction and evolution of the considered planes versus time. More particularly, we used a FFT analysis of the images to identify all the planes present (Fig. 5h-n). A mask was applied to the chosen diffraction spots, which was also used to measure the inter-reticular distance $d$. We then superposed the contribution of each plane family to the real images from Fig. 5a-g (Fig. 5o-u). Metallic $\mathrm{Ru}$ is clearly identified by the (001) planes with a distance $d=$ $0.235 \mathrm{~nm}$. It is represented in red in Fig. 50-u and characterized with red arrows in Fig. 5h-n. Two other planes are also distinguished at 0.195 and $0.216 \mathrm{~nm}$ (green arrows and circles in Fig. 5h-n). Both distances and angles unambiguously correspond respectively to the (011) and (100) $\mathrm{Ru}_{2} \mathrm{C}$ planes (JCPDS 04-019-7840). $\mathrm{Ru}_{2} \mathrm{C}$ is represented in green in the reconstructed presentation of the nanoparticle in Fig. 5o-u.

At the beginning of our observation (injection of $\mathrm{H}_{2} / \mathrm{CO}$ gas at $500{ }^{\circ} \mathrm{C}$ ), the nanoparticle appears as a complex mixture of metallic $\mathrm{Ru}$ and $\mathrm{Ru}$ carbide (the grey color may correspond to an amorphous part). The CNT growth starts directly from $\mathrm{Ru}_{2} \mathrm{C}$. After $16 \mathrm{~s}$, most of the nanoparticles consist of the metallic phase surrounded by $\mathrm{Ru}_{2} \mathrm{C}$. This initial period of time corresponds to a high rate for the growth of carbon nanostructures. The reconstruction direction is pointed at with black arrows (Fig. 5a-d). This reconstruction was accompanied by contrast changes observed among $t_{0}$ (Fig. 5a), $t=2 \mathrm{~s}$ (Fig. 5b) and $t=13 \mathrm{~s}$ (Fig. $5 \mathrm{~d}$ ). The velocity of this wave reconstruction was estimated to be about $0.9 \mathrm{~nm} \mathrm{~s}^{-1}$ (see Video S3 in the ESI $\dagger$ ).

As previously mentioned, $\mathrm{Ru}_{2} \mathrm{C}$ generally appears around the metallic $\mathrm{Ru}$ particle, with the spatial distribution varying in time, and coexists in the presence of a few graphitic layers ( 1 to 3 layers). In addition, no graphitic layer was observed at the nanoparticle surface from metallic Ru planes (Fig. 5r and $\mathrm{u}$ ), immediately after the total disappearance of the carbide phase. Thus, the presence of the Ru carbide phase is asserted. It is identified here for the first time during the CNT growth at atmospheric pressure, ${ }^{46}$ as directly responsible for the formation of the graphitic planes at the particle surface and consequently for the CNT appearance and growth. The existence of the $\mathrm{Ru}$ metallic phase can be assigned to the carbon dissolution phase inside the particle during the period of time characterized by a lower growth rate.

A very important finding is that the mean period of the particle restructuration (between Fig. 5p and s or between $\mathrm{s}$ and $\mathrm{u}$ ) is very similar to that of the roughly cyclic variation of the growth rate. Therefore, this cyclic growth kinetics can be related to the particle transformation and restructuration due to two processes which are in competition, the dissolution and the rejection of carbon atoms inside the particle.

\subsection{Main result: a relaxation oscillation CNT growth model}

This paper presents the in situ analysis of the carbon nanotube growth process on $\mathrm{Ru}$ nanoparticles from a mixture of $\mathrm{CO}-\mathrm{H}_{2}$ at atmospheric pressure and $500{ }^{\circ} \mathrm{C}$. The first information we obtained is that - within the 1-10 nm range - the growth rate is independent of the $\mathrm{Ru}$ particle size. However, Mabudafashi et $a l .{ }^{38}$ showed that a particle size larger than $30 \mathrm{~nm}$ is required for the growth of similar structures under a propene atmosphere. This difference in our observation can be explained by the nature of the gas precursor used to grow the
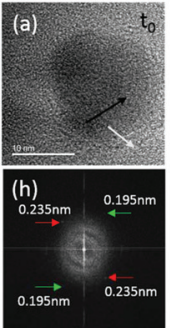

(a)

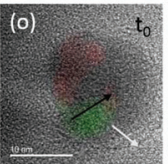

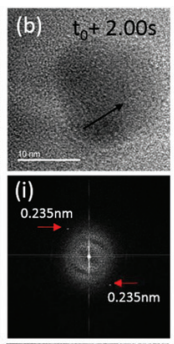
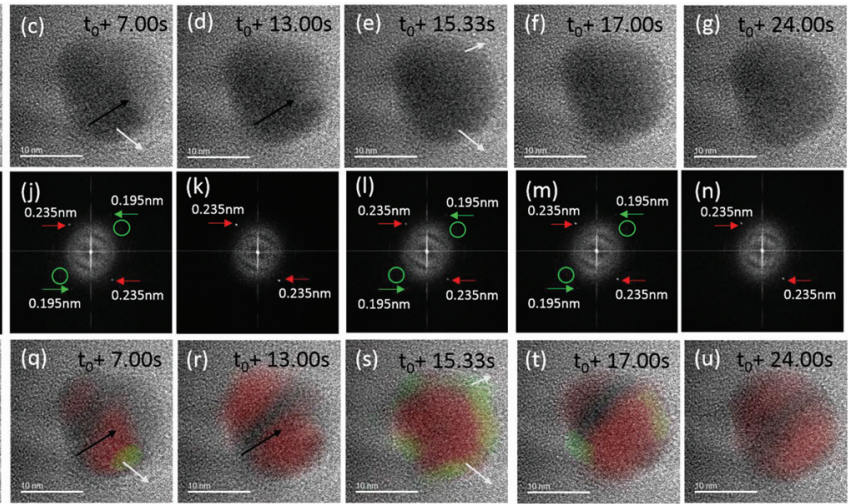

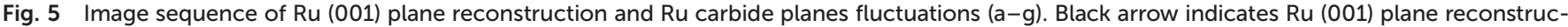

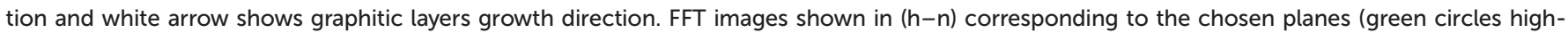

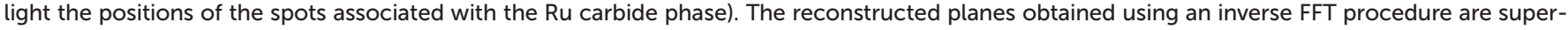
posed on the real images $(\mathrm{O}-\mathrm{u})$ with metallic Ru planes in red and the carbide ones in green. 


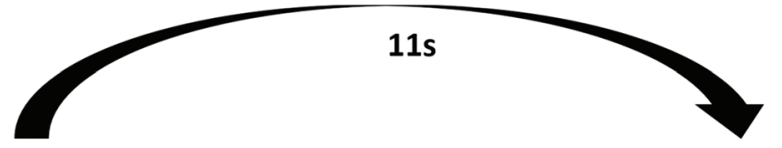

(a)

(b)

(c)

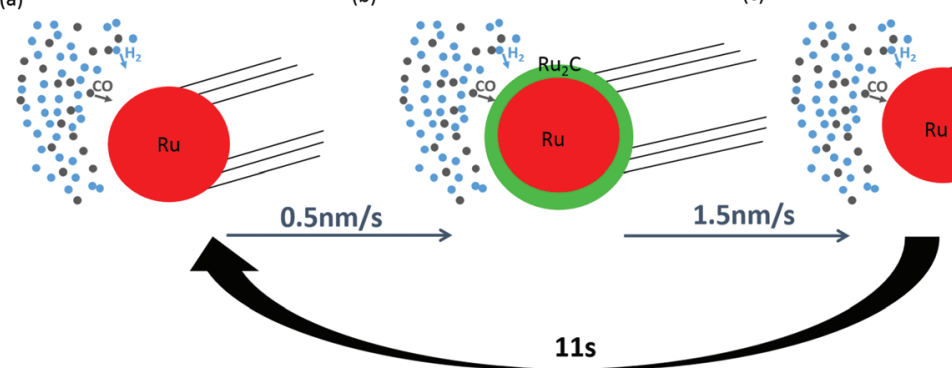

Fig. 6 Schematic representation of the "cyclic" mechanism for the CNT growth catalyzed by Ru nanoparticles: (a) dissociation of $\mathrm{CO}$ and $\mathrm{H}_{2}$ molecules, (b) formation of the unstable $\mathrm{Ru}_{2} \mathrm{C}$ phase (green), and (c) rejection of the carbon atoms.

carbon nanostructures. Peng et $a l .{ }^{47}$ showed that the growth of carbon based nanostructures using Pt nanoparticles depends on the particle size. For particles less than $2 \mathrm{~nm}$, graphene layers formed on the particle surface are transported to the support. For particles between 2 and $6 \mathrm{~nm}$, the graphene layers do form carbon nanotubes. For particles larger than $6 \mathrm{~nm}$, multiple graphene layers do encapsulate the particles. There is no solubility of carbon in $\mathrm{Pt}^{48}$ and this is enough for explaining the particle size dependence compared to the size independence for $\mathrm{Ru}$.

The evolution of the particle shape and the size and crystallinity fluctuation (Fig. 3) support the carbon dissolution hypothesis. However, the step edge formation (Fig. 4) was attributed by Helveg et al. to the migration of carbon atoms on the surface of the particle. ${ }^{19}$ In our case, the identification of the unstable $\mathrm{Ru}_{2} \mathrm{C}$ structure (Fig. 5) enhances the carbon dissolution and diffusion processes inside the $\mathrm{Ru}$ particles. The growth model we propose in Fig. 6 is thus based on the instability of the $\mathrm{Ru}_{2} \mathrm{C}$ structure, which leads to an oscillating carbon rejection towards the surface, once the spatial extension of the carbide phase reaches some threshold value. This oscillating rejection can be assigned to a repetitive relaxation mechanism between a thermodynamically unstable phase and a stable one. This leads to a similar oscillating behavior of the growth rate. From the phenomenological point of view, the carbon monoxide dissociated on the surface of the particles provides carbon atoms that do diffuse inside the particles and do stabilize for a short period of time the Ru carbide structures that eventually act as a carbon reservoir. The growth of the graphitic layers actually occurs when this structure rejects the carbon atoms, allowing for the $\mathrm{Ru}$ atoms to reconstruct their metallic phase. Note that, in the first approximation, this structural metal-carbide transition, though inhomogeneous within the particle, is a quite periodical event and has a mean relaxation time which coincides with the observed fluctuations in the CNT growth rate.

Though quite similar particle shape and size fluctuations have been observed before, it was difficult from our data to reveal a cyclic behavior and specially to estimate a characteristic mean time. However, as demonstrated before, the shape fluctuation can be directly related to the direction change of the particle during the growth process.

Finally, the very dynamical behavior at the particle level strongly suggests that the sub-surface planes of $\mathrm{Ru}$ particles are in a liquid-like state during the growth of carbon nanostructures such that a core-shell structure can be assigned (with a quasi-solid core and the liquid-like shell). Even far from the bulk melting temperature of $\mathrm{Ru}\left(2250^{\circ} \mathrm{C}\right)$, the particles may exhibit a liquid-like behavior at their surface. The associated high atom mobility explains that the particles are able to reconstruct easily into the solid phase, even if the temperature is below the Tamman temperature.

\section{Conclusion}

In situ carbon nanostructures with a fishbone-type structure were grown from $\mathrm{CO} / \mathrm{H}_{2}$ at atmospheric pressure and at $500{ }^{\circ} \mathrm{C}$ using $\mathrm{Ru}$ nanoparticles as a catalyst. Particle shape and size fluctuation have been observed, in relation to the direction change of the particle during the growth process and with the final shape of the CNT. More importantly, a relaxation oscillation of the growth rate has been observed and correlated with the metal-carbide structural transition at the sub-surface of the particle. For the first time, an unstable Ru carbon structure was identified as $\mathrm{Ru}$ carbide and its presence seems to be mandatory for the activation of the growth of carbon nanostructures. An unconventional growth model was proposed that takes into account the high instability of this $\mathrm{Ru}_{2} \mathrm{C}$ phase which acts as a relaxing supply for the growth of carbon nanostructures, once a critical threshold carbon concentration within the particle is reached. From a more general point of view, this study demonstrates once again the variety of phenomenological models and catalyst behaviors used for the growth of carbon nanostructures with different morphological and structural characteristics. 
1 Conflicts of interest

The authors declare no competing financial interest.

\section{Acknowledgements}

The authors would like to thank the French ANR (National Research Agency) under the 3DCLEAN project 15-CE09-0009-01 for financial support.

\section{References}

1 Understanding Carbon Nanotubes: From Basics to Applications, ed. A. Loiseau, Springer, Berlin, New York, 2006.

2 L. S. Lobo, Carbon, 2017, 114, 411-417.

3 Y.-M. Lin, J. Appenzeller, J. Knoch and P. Avouris, IEEE Trans. Nanotechnol., 2005, 4, 481-489.

4 Y. Hayamizu, T. Yamada, K. Mizuno, R. C. Davis, D. N. Futaba, M. Yumura and K. Hata, Nat. Nanotechnol., 2008, 3, 289-294.

5 V. Lovat, D. Pantarotto, L. Lagostena, B. Cacciari, M. Grandolfo, M. Righi, G. Spalluto, M. Prato and L. Ballerini, Nano Lett., 2005, 5, 1107-1110.

6 J. Ji, X. Duan, G. Qian, X. Zhou, D. Chen and W. Yuan, Ind. Eng. Chem. Res., 2013, 52, 1854-1858.

7 V. Jourdain and C. Bichara, Carbon, 2013, 58, 2-39.

8 R. Sharma and Z. Iqbal, Appl. Phys. Lett., 2004, 84, 990-992.

9 S. W. Pattinson, R. E. Diaz, N. A. Stelmashenko, A. H. Windle, C. Ducati, E. A. Stach and K. K. K. Koziol, Chem. Mater., 2013, 25, 2921-2923.

10 M. He, H. Jiang, B. Liu, P. V. Fedotov, A. I. Chernov, E. D. Obraztsova, F. Cavalca, J. B. Wagner, T. W. Hansen, I. V. Anoshkin, et al., Sci. Rep., 2013, 3, DOI: 10.1038/ srep01460.

11 M. Z. M. Yusop, P. Ghosh, Y. Yaakob, G. Kalita, M. Sasase, Y. Hayashi and M. Tanemura, ACS Nano, 2012, 6, 95679573.

12 L. Zhang, P.-X. Hou, S. Li, C. Shi, H.-T. Cong, C. Liu and H.-M. Cheng, J. Phys. Chem. Lett., 2014, 5, 1427-1432.

13 M. Diarra, A. Zappelli, H. Amara, F. Ducastelle and C. Bichara, Phys. Rev. Lett., 2012, 109, 185501.

14 V. Balakrishnan, M. Bedewy, E. R. Meshot, S. W. Pattinson, E. S. Polsen, F. Laye, D. N. Zakharov, E. A. Stach and A. J. Hart, ACS Nano, 2016, 10, 11496-11504.

15 M. Bedewy, B. Viswanath, E. R. Meshot, D. N. Zakharov, E. A. Stach and A. J. Hart, Chem. Mater., 2016, 28, 38043813.

16 S. Hofmann, R. Sharma, C. Ducati, G. Du, C. Mattevi, C. Cepek, M. Cantoro, S. Pisana, A. Parvez, F. CervantesSodi, et al., Nano Lett., 2007, 7, 602-608.

17 D.-M. Tang, C. Liu, W.-J. Yu, L.-L. Zhang, P.-X. Hou, J.-C. Li, F. Li, Y. Bando, D. Golberg and H.-M. Cheng, ACS Nano, 2014, 8, 292-301.
18 S. Hofmann, R. Blume, C. T. Wirth, M. Cantoro, R. Sharma, C. Ducati, M. Hävecker, S. Zafeiratos, P. Schnoerch, A. Oestereich, et al., J. Phys. Chem. C, 2009, 113, 1648-1656.

19 S. Helveg, C. López-Cartes, J. Sehested, P. L. Hansen, B. S. Clausen, J. R. Rostrup-Nielsen, F. Abild-Pedersen and J. K. Nørskov, Nature, 2004, 427, 426-429.

20 H. Yoshida, S. Takeda, T. Uchiyama, H. Kohno and Y. Homma, Nano Lett., 2008, 8, 2082-2086.

21 H. Yoshida, H. Kohno and S. Takeda, Micron, 2012, 43, 1176-1180.

22 Y. Kohigashi, H. Yoshida, Y. Homma and S. Takeda, Appl. Phys. Lett., 2014, 105, 073108.

23 P. A. Lin, J. L. Gomez-Ballesteros, J. C. Burgos, P. B. Balbuena, B. Natarajan and R. Sharma, J. Catal., 2017, 349, 149-155.

24 P. A. Buffat and J. P. Borel, Phys. Rev. A: At., Mol., Opt. Phys., 1976, 13(6), 2287-2298.

25 Z. L. Wang, J. M. Petroski, T. C. Green and M. A. El-Sayed, J. Phys. Chem. B, 1998, 102(32), 6145-6151.

26 H. Reiss, P. Mirabel and R. L. Whetten, J. Phys. Chem., 1988, 92(26), 7241-7246.

27 K. K. Nanda, S. H. Sahu and S. S. Behera, Phys. Rev. A, 2002, 66, 013208.

28 R. T. K. Baker, J. Catal., 1982, 78, 473-476.

29 R. T. K. Baker, Carbon, 1989, 27, 315-323.

30 R. S. Wagner and W. C. Ellis, Appl. Phys. Lett., 1964, 4, 89-90.

31 F. Wang, A. Dong and W. E. Buhro, Chem. Rev., 2016, 116, 10888-10933.

32 X. Feng, S. W. Chee, R. Sharma, K. Liu, X. Xie, Q. Li, S. Fan and K. Jiang, Nano Res., 2011, 4, 767-779.

33 T. Ichihashi, J. Fujita, M. Ishida and Y. Ochiai, Phys. Rev. Lett., 2004, 92, DOI: 10.1103/PhysRevLett.92.215702.

34 H. Dai, A. G. Rinzler, P. Nikolaev, A. Thess, D. T. Colbert and R. E. Smalley, Chem. Phys. Lett., 1996, 260, 471-475.

35 F. Z. Bouanis, L. Baraton, V. Huc, D. Pribat and C. S. Cojocaru, Thin Solid Films, 2011, 519, 4594-4597.

36 F. Z. Bouanis, C. S. Cojocaru, V. Huc, E. Norman, M. Chaigneau, J.-L. Maurice, T. Mallah and D. Pribat, Chem. Mater., 2014, 26, 5074-5082.

37 Y. Qian, C. Wang, G. Ren and B. Huang, Appl. Surf. Sci., 2010, 256, 4038-4041.

38 M. L. Mabudafhasi, R. Bodkin, C. P. Nicolaides, X.-Y. Liu, M. J. Witcomb and N. J. Coville, Carbon, 2002, 40, 2737-2742.

39 C. Sassoye, G. Muller, D. P. Debecker, A. Karelovic, S. Cassaignon, C. Pizarro, P. Ruiz and C. Sanchez, Green Chem., 2011, 13, 3230.

40 A. Kim, C. Sanchez, G. Patriarche, O. Ersen, S. Moldovan, A. Wisnet, C. Sassoye and D. P. Debecker, Catal. Sci. Technol., 2016, 6, 8117-8128.

41 A. Kim, D. P. Debecker, F. Devred, V. Dubois, C. Sanchez and C. Sassoye, Appl. Catal., B, 2018, 220, 615-625.

42 L. F. Allard, S. H. Overbury, W. C. Bigelow, M. B. Katz, D. P. Nackashi and J. Damiano, Microsc. Microanal., 2012, 18, 656-666.

43 A. K. Schaper, H. Hou, A. Greiner and F. Phillipp, J. Catal., 2004, 222, 250-254. 
44 P. Pinheiro, M. C. Schouler, P. Gadelle, M. Mermoux and E. Dooryhée, Carbon, 2000, 38, 1469-1479.

45 J. P. Pinheiro, M. C. Schouler and P. Gadelle, Carbon, 2003, 41, 2949-2959.

46 N. R. Sanjay Kumar, N. V. Chandra Shekar, S. Chandra, J. Basu, R. Divakar and P. C. Sahu, J. Phys.: Condens. Matter, 2012, 24, 362202.
47 Z. Peng, F. Somodi, S. Helveg, C. Kisielowski, P. Specht and A. T. Bell, J. Catal., 2012, 286, 22-29.

48 "Wiley: Kirk-Othmer Encyclopedia of Chemical Technology, Index to Volumes 1-26, 5th Edition Kirk-Othmer," can be found under http://www.wiley. com/WileyCDA/WileyTitle/productCd-0471484962.html, n.d. 